\title{
Original article \\ Parkinson's disease severity and motor subtype influence physical capacity components
}

\author{
Marcelo Pinto Pereira \\ Paulo Henrique Silva Pelicioni \\ Lilian Teresa Bucken Gobbi \\ São Paulo State University, Brazil
}

\begin{abstract}
The severity of Parkinson's disease (PD) and PD's motor subtypes influence the components of physical capacity. The aim of this study was to investigate the impact of both PD severity and motor subtype in the performance of these components. Thirty-six PD patients were assigned into four groups: Tremor (TD) initial and TD mild, akinetic-rigid (AR) initial, and AR mild. Patients' strength, balance, coordination, mobility and aerobic capacity were evaluated and groups were compared using a two-way ANOVA (severity and subtype as factors). AR presents a poorer performance than TD in almost all tests. Also this performance was worsened with the advance of the disease in AR, contrary to TD. We conclude that AR and TD subgroups are different about their performance on physical capacity components, moreover, this performance worsens with the advance of the disease of the AR group, but not for TD.
\end{abstract}

Keywords: physical capacity, Parkinson's disease, motor subtype, disease stage

Resumo- “Agravo da doença de Parkinson e subtipo motor influencia componentes da capacidade física.” A doença de Parkinson (DP) é caracterizada por diferentes subtipos motores e supõe-se que o desempenho dos componentes da capacidade física é influenciado por esses subtipos. O objetivo desse estudo foi investigar o impacto que a severidade e o subtipo da DP podem trazer sobre o desempenho dos componentes da capacidade física. Trinta e seis pacientes com DP foram distribuídos em quarto grupos: com dominância de tremor (TD) inicial e TD intermediário ou acinesia (AR) inicial e AR intermediário. A força, equilíbrio, coordenação, mobilidade e capacidade aeróbia foram avaliados. AR apresentou um pior desempenho que TD em nos testes. Esse desempenho foi pior com o aumento da severidade da doença em AR, mas não em TD. Conclui-se que os grupos AR e TD são diferentes em relação ao desempenho dos componentes da capacidade física, mas principalmente, esse desempenho piora com o avanço da doença em AR, mas não em TD.

Palavras-chaves: capacidade física, doença de Parkinson, subtipo motor, estágio da doença

\begin{abstract}
Resumen- - "Empeoramiento de la enfermedad de Parkinson y componentes de subtipo motor influencia la condición física." La enfermedad de Parkinson (EP) se caracteriza por subtipos motor, y se supone que el rendimiento de los componentes físicos de capacidad es influenciada por aquellos subtipos. El objetivo de este estudio fue investigar el impacto tanto de la severidade y subtipo de la PD en el rendimiento de estos componentes. Treinta y seis pacientes con EP se distribuyeron en: Temblor (TD) inicial y TD suave, acinesia (AR) inicial y AR suave. Fuerza, equilibrio, coordinación, la movilidad y la capacidad aeróbica fueron evaluados. AR presenta un desempeño más pobre que TD en las pruebas. También este comportamiento se agravó con el avance de la enfermedad en AR, diferente que en TD. Como conclusión AR y TD son diferentes en respecto a su rendimiento en los componentes físicos de capacidad, pero sobre todo, esto empeora con el aumento de avance de la enfermedad en el grupo de AR, pero no en TD.
\end{abstract}

Palabras claves: capacidad física, enfermedad de Parkinson, subtipo motor, estadio de la enfermedad

\section{Introduction}

Parkinson's disease (PD) is the second most prevalent neurodegenerative disease among elderly (Olanow, Stern, \& Sethi, 2009). PD is mainly characterized by the death of neurons in the substancia nigra pars compacta, leading to a series of motor impairments, such as bradikynesia, rigidity, resting tremor and postural instability (Gobbi, Barbieri,
Vitório, Pereira, \& Teixeira-Arroyo, 2011; Waters, 2008). However, since most PD patients are elderly, their independence in daily life can also be influenced by others physiological aging processes, such as the decline of physical capacity components: strength, coordination, balance and aerobic capacity (Rantanen et al., 1999). Barbieri et al. (2012) showed the importance of evaluating these components to properly manage rehabilitation/preventive 
exercise programs for this specific population. These authors also showed that these components deteriorate as the disease advances. However, they failed to investigate whether the PD motor subtype could also affect the physical capacity components of these patients.

PD is characterized by its heterogeneity, and two main motor subtypes are distinguished (Benninger, Thees, Kollias, Bassetti, \& Waldvogel, 2009; Eggers, Kahraman, Fink, Schmidt, \& Timmermann, 2011; S. J. Lewis et al., 2005): akinetic-rigidity (AR) and tremor-dominant (TD) subtypes. AR is mainly characterized by a reduction in the movement velocity (bradykinesia), difficulties in the initiation of movements (akinesia) and an increase in muscle tone (rigidity). In another way, TD presents a resting or postural tremor in the head, trunk or limbs that can vary between 4-5 to $8-10 \mathrm{~Hz}$ (Helmich, Hallett, Deuschl, Toni, \& Bloem, 2012). Patients can have either primary rigidity and bradykinesia with minimal tremor or tremor with minimal rigidity (Lewis et al., 2011). In some cases AR patients show no tremor during their entire lifetime (Helmich et al., 2012). It is accepted that both subgroups are distinguished by different morphological factors (Benninger et al., 2009): AR patients present disturbances in the striatum-thalamo-cortical pathway, while TD patients have deficits in the cerebellum-thalamo-cortical pathway (Benninger et al., 2009; Eggers et al., 2011; Lewis et al., 2011). Both these groups also present differences in non-motor symptoms: AR patients have more depression, anxiety, higher cognitive impairment, lower attention and present a faster rate of disease progression (Alves, Larsen, Emre, Wentzel-Larsen, \& Aarsland, 2006; Burn et al., 2012; Jankovic \& Kapadia, 2001). However, beyond the high number of studies showing subgroups differences and their effect on functional status, balance and cognitive domains, there is a lack of information in the literature about their influence on the physical capacity components, which influence mobility as much as the disease symptoms. Since AR patients have greater motor impairments and these are related to the physical capacity components, it is believed that these components are more influenced by disease symptoms in the AR than in the TD groups. Also, since AR patients experience a more rapid advance of the disease (Jankovic \& Kapadia, 2001), it is believed that these components worsen in this group sooner than they do for the TD patients. However, to our knowledge this is the very first study to investigate the influence of both PD subtype and disease stage on the performance of physical capacity components. Understanding these involvements is highly important to both physicians and patients, since it leads to precise prescribing for rehabilitation and preventive exercise programs to meet patients' needs.

In this way, this study has two main objectives: i) to investigate in PD patients the influence of both motor subtype and progression of the disease in specific components of physical capacity as balance, strength, coordination and aerobic status; and also: ii) to correlate the performance of these physical components with clinical variables to clarify if the impairments presented by AR and
TD are more related to the disease itself or by the aging process. As main hypothesis it is believed that AR patients will present a lower status in the physical capacity components, especially with the disease advance, and those will be more related to clinical status in AR than in TD patients.

\section{Method}

\section{Participants}

Thirty-six patients participated in this study and were assigned to different groups considering both PD motor subtype (akinetic-rigidity and tremor-dominant) and disease stage (initial [Hoehn and Yahr scale (HY): 1 - 1.5] and mild [HY scale: 2-3]). Therefore, four groups were created: ARinitial $(n=10)$, AR-mild ( $n=7)$, TD-initial $(n=10)$ and TD-mild $(n=9)$. Patients in all groups had similar age, height, bodymass and cognitive status. Also, AR-initial was similar to TD-initial for disease features (disease stage and disease impairments). The same was seen for the mild groups. Patients were invited to participate in the study by public announcements in newspapers, radio and television. Fortysix subjects responded to the invitation, but ten (6 AR and 4 TD) had to be excluded to maintain the similarity among all groups. Patients signed an informed consent form approved by the local ethics committee prior to the application of any procedures. The inclusion criteria included both men and women who have had a clinically confirmed diagnosis of PD and were able to walk independently. The Modified Baecke Questionnarie for Older Adults (Baecke) (Voorrips, Ravelli, Dongelmans, Deurenberg, \& Van Staveren, 1991) was used to identify the subjects' physical activity level.

To assure clinical diagnosis, all patients were screened by a full examination consisting of a general questionnaire on overall health, clinical history, neurological examination and were screened by a trained health professional (whose was blinded for the purpose of the experiment) to obtain the total Unified Parkinson's Disease Scale (UPDRS) and the HY scale. Patients were also screened about their cognitive functions using the Mini-Mental State Examination - MMSE (Folstein, Folstein, \& McHugh, 1975) - no dementia signals were detected.

Patients were classified into the subgroups using the UPRDS section III (motor subscale): tremor was assessed by the mean of two items (20 and 21 - and their sub-items: total of seven scores) and nontremor was assessed by mean of eight items $(18,19,22,27,28,29,30$ and 31 considering their sub-items: total of twelve scores). Then a ratio between tremor and non-tremor score was determined. Patients were classified as TD if presenting a score $>1.0$ and as AR if $<0.8$ (Eggers et al., 2011; Lewis et al., 2011).

\section{Procedures}

All procedures were undertaken in a single day and patients were in the "on" phase of their medication during 
all procedures, performed about one hour after their drug intake. The physical fitness components, cognitive screening and clinical evaluation were assessed using tests fully described elsewhere, but briefly:

- Upper limb muscular strength: female participants had to lift a 4-lb barbell and male participants an 8-lb barbell, using a biceps curl motion. Patients had to perform as many repetitions as possible in 30 seconds. The numbers of repetitions was scored (Barbieri et al., 2012; Osness et al., 1990).

- Lower limb muscular strength: patients were seated in an armless chair, looking straight ahead, with arms crossed over the chest and feet on the ground. After the examiner's signal, patients had to rise as quickly as possible until achieving complete knee and back extension and then sit back until their posterior thigh touches the chair. Patients had to perform as many repetitions as possible in 30 seconds (Rikli \& Jones, 1999).

- Coordination test: this test used a homemade rectangular object $32 \mathrm{~cm}$ long, $18 \mathrm{~cm}$ wide and $5 \mathrm{~cm}$ high placed in front of the subject (seated comfortably on a chair). In this object there are two rows of small holes (10 each) $15 \mathrm{~cm}$ distant from each other. Each hole has a diameter of $1.2 \mathrm{~cm}$ and is $3.2 \mathrm{~cm}$ distant from the next one. In the row distant from the subject, 10 small pieces of wood $(1 \mathrm{~cm}$ on diameter and $7 \mathrm{~cm}$ high) is placed inside its corresponding hole. Subjects are supposed to move the pieces of wood, one at a time, as quickly as possible to the row next to them. Starting with the right hand, the pieces should be moved from right to left and vice versa. Time to complete the task is timed. After a learning attempt, each subject performed three valid attempts for each hand (Bryden \& Roy, 2005). The mean of the three attempts was considered.

- Six minutes walking test (6MWT): this test evaluates the patients' capacity to walk the maximum distance in 6 minutes. The patients walked in a $30 \mathrm{~m}$ path without running; two cones were placed at the beginning and end of the path. They were asked to walk to a cone, turn around come back to the start and then continue. They did this until the end of the 6-minute period. If required, subjects could use walking aids. Throughout the task, patients were followed by the examiner who gave verbal encouragement and reported the time remaining only after the third minute. The entire path was marked every $3 \mathrm{~m}$ and the total walking distance was obtained ("ATS statement: guidelines for the six-minute walk test," 2002).

- Functional mobility test (Timed Up and Go test - TUG): The task consisted of the participant standing up from a sitting position from an armless chair with a seat height of $46.5 \mathrm{~cm}$, walking a distance of $3 \mathrm{~m}$, turning around the cone, returning, and sitting back down in the chair. Participants were instructed to perform the test as quickly as possible, but without running. At least one practice trial was offered to the participants at the beginning of the procedure so that they could become familiar with it. Three trials were given and performance time was measured in seconds. Time was recorded from the instant the person's buttocks left the chair (standing up) until the next contact with the chair (sitting down). The mean value of the three trials was considered for statistical analysis. (Podsiadlo \& Richardson, 1991).

- Balance status (Berg Balance Scale - BBS): This scale evaluates the individual capacity to maintain balance while executing 14 tasks of increasing difficulty. Each task is scored between 0 and 4 and indicates the capacity of an individual to execute tasks independently. A total score of 56 is possible and higher scores point to better balance status (Qutubuddin et al., 2005; Scalzo et al., 2009)

- Cognitive screening (Mini Mental Exam Examination MMSE): a brief 30-point questionnaire to evaluate spatial and temporal orientation, memory, language, attention, ability to do calculations and constructive visual capacity. Scores under 24 means that the subject has its mental capacity impaired. Scores above 24 means that the subject is mentally "intact" (Folstein et al., 1975).

- Attention status (Attention): The Wechsler Adult Intelligence Scale - III - sub-test 1 - Searching for Symbols) was used. This test is composed of a series of symbols arranged in groups. In each series, 2 model and 5 answer symbols are presented. The patient is supposed to find at least one answer that matches the model symbols. In an affirmative case (when the patient finds a model symbol in the answers) the subject says "yes". In a negative case, the subject is supposed to say "no". During the test, subjects were instructed to look for the symbols as fast as they could with a 2-minute time limit. The number of correct answers was scored (Spreen \& Strauss, 1998).

- Mental flexibility (Wisconsin Card Sorting Test WCST): this test specifically assesses abstract mental flexibility. An impaired abstract mental flexibility means that a subject has a lower capacity to change its behavior/strategy when trying to resolve a problem. In another words, the subject cannot realize that the strategy currently used is not the best in that case. It consists of 4 stimulus cards and 128 response cards that must be combined with the stimulus cards by following the hints "right" or "wrong" provided by the evaluator. From this hint, without pre-established rules, the participant must find the right combinations (according to color, shape or number). Every 10 consecutive hits, the evaluator changes the mix and the participant must change his/her strategy. The test continues until the participant completes 6 categories of combinations or completes the 128 attempts. Mental flexibility was assessed by the percentage of perseverative errors made by patients. (Heaton, Chelune, Tlley, Kay, \& Curtiss, 1993; Paolo, Troster, Axelrod, \& Koller, 1995).

- Depression and anxiety level (Hospital Anxiety and Depression Scale - HADS-A and HADS-D): The test consists of 14 items (seven for assessing anxiety, and seven for depression), ranging from 0 (no problem) to 3 (severe problem). Scores of up to 9 points on each scale are representative of symptoms of anxiety and depression. (Zigmond \& Snaith, 1983).

- Unified Parkinson's disease scale (UPDRS): This scale ranges from 0 to 176 points and is divided in 3 subscales: 
mental (16 points), activities of daily life (52 points), motor (UPDRS-III) (108 points); higher score indicates greater impairment ("The Unified Parkinson's Disease Rating Scale (UPDRS): status and recommendations," 2003).

- HY scale: PD severity was evaluated using the modified HY scale. This scale ranges from 0 (no signs of disease) to 5 (needing a wheelchair or bedridden unless assisted) in order to indicate a relative level of disability (Goetz et al., 2004; Hoehn \& Yahr, 1967).

\section{Statistical analyzes}

All results are expressed as mean $(+\mathrm{SD})$. Statistical procedures were undertaken in the Statistica 7.0 for windows. After confirm a normal data distribution (Shapiro-wilk test) groups were compared for all variables using two-way ANOVAs tests (with disease stage and disease subtype as factor). Also, correlations between age and clinical variables (age of onset, disease time, UPRS-III and HY) with the performance in the physical capacity components tests (UpperTest, LowerTest, Pegboard, 6MWT, TUG and BBS) were conducted through the Pearson correlation test. For all tests a $p<0.05$ was considered statistically significant.

\section{Results}

Table 1 shows the patients' anthropometric and clinical outcomes. No difference was found for age, height, weight, Attention, WSCT, MMSE, HADS-A and HADS-D. All participants were not enrolled in any physical training program for at least 3 months - beware the AR initial group presented a more active life style (higher score), no differences were found between groups in the Baecke (Table 1). Otherwise, as expected for HY, UPDRS and UPDRS-III a main effect of disease stage was found. This effect was also observed for age of onset. No subtype effect or interaction between factors was found.

Performance of all components of physical capacity is shown in Figure 1. A main effect of disease subtype was found for BBS $(\mathrm{F}=14.68 ; p<0.001)$ and $6 \mathrm{MWT}(\mathrm{F}=5.85 ; p$ $=0.02)$. For TUG $(\mathrm{F}=9.05 ; p=0.005), \operatorname{UpperTest}(\mathrm{F}=7.76 ; p$ $=0.04)$, LowerTest $(\mathrm{F}=4.28 ; p=0.04), 6 \mathrm{MWT}(\mathrm{F}=27.00 ; p<$ $0.001)$ and BBS (F = 17.58; $p<0.001)$ an effect of disease stage was found. However, the most interesting result is the interaction between factors for Pegboard $(\mathrm{F}=6.95 ; p=0.01)$, BBS $(\mathrm{F}=27.44 ; p<0.001)$, UpperTest $(\mathrm{F}=4.23 ; p=0.04)$ and $6 \mathrm{MWT}(\mathrm{F}=12.39 ; p=0.001)$. These results clearly show a poorer performance with the disease severity in AR, whereas in TD maintenance is seen.

Table 2 expresses the results of correlation tests between age, disease time, HY and UPDRS-III with the performance of physical capacities tests. It can be seen that in general, the performance in the tests are more linked to clinical status and impairments in AR, whereas in TD this link is not so evident. For TD weak correlations were found ( 0.47), whereas for AR, these coefficients ranged from 0.44 to 0.79 .
Similarly, significant correlations were found between age and tests performance only for TD.

\section{Discussion}

The aim of this study was to investigate the impact of both PD motor subtype and severity of disease on the performance of physical capacity components. As the main result we found that akinetic-rigid (AR) patients generally have lower performance than tremor-dominant (TD), especially when the disease severity is higher. Also, AR presents a closer relationship between physical capacity components and disease impairments than TD. Based on the recent literature that TD presents lesions in brain areas other than the striato-thalamic-cortical pathway (Benninger et al., 2009; Helmich et al., 2012; Lewis et al., 2011) and that this group presents a higher performance in the tests described here, mainly with the disease advance, two hypothesis were developed to explain our results: i) the striato-thalamic-cortical pathway has a closer relation with the physical capacity components performance; ii) the ageing process develops faster in AR patients.

As a first result, we found a poorer performance on physical capacity tests in the mild over the initial disease stage. These results are in agreement with the results of Barbieri et. al (2012) and seems to be obvious, since PD is a progressive disease, mainly characterized by the development of motor symptoms. Barbieri et al. (2012) clearly confirmed this hypothesis showing that performance on physical capacity components tests is closely related to disease stage and motor impairments. However, according to our results this is not true for all patients: only AR presents a moderate to strong relationship between motor impairment and performance on the physical capacity components tests. Here, we showed the importance of evaluating these two groups separately: possibly they have different needs for assistance and care.

This result could be explained by the recent theories that TD forms lesions in structures other than the striato-thalamocortical pathway (Benninger et al., 2009; Helmich et al., 2012; Lewis et al., 2011). These studies had clearly showed that tremor is not dependent on dopamine uptake in the striatum (Helmich, Janssen, Oyen, Bloem, \& Toni, 2011), rather it is more closely related to pallidal dopamine and to the serotonergic system (Helmich et al., 2011). Therefore, we suggest that others structures are more prone to determining performance of physical capacity components in TD. However, the methods used in our study cannot lead to any confirmation of this hypothesis and it should be taken in account in future studies.

The main result of our study is that the performance of AR patients worsens for almost all physical capacity components as the disease advances, whereas TD patient performance does not. Some studies have compared the rate of disease progression and motor impairments in both motor subgroups, showing that AR presents a stepper clinical advance than TD (Alves et al., 2006; Gray et al., 2009; 
Table 1. Anthropometric, cognitive and clinical variables.

\begin{tabular}{|c|c|c|c|c|c|c|c|}
\hline & \multicolumn{2}{|c|}{ Akinetic-rigid } & \multicolumn{2}{|c|}{ Tremor-dominant } & \multirow[b]{2}{*}{ Stage } & \multirow[b]{2}{*}{ Subtype } & \multirow{2}{*}{$\begin{array}{c}\text { Stage } \\
\mathrm{x} \\
\text { Subtype } \\
\end{array}$} \\
\hline & Initial & Mild & Initial & Mild & & & \\
\hline $\begin{array}{l}\text { Age } \\
\text { (years) }\end{array}$ & $\begin{array}{l}69.81 \\
(4.18)\end{array}$ & $\begin{array}{l}72.00 \\
(4.89)\end{array}$ & $\begin{array}{l}70.20 \\
(6.12)\end{array}$ & $\begin{array}{l}73.00 \\
(5.52)\end{array}$ & 0.16 & 0.69 & 0.86 \\
\hline $\begin{array}{l}\text { Height } \\
\text { (m) }\end{array}$ & $\begin{array}{c}1.64 \\
(0.10)\end{array}$ & $\begin{array}{c}1.52 \\
(0.94)\end{array}$ & $\begin{array}{c}1.62 \\
(0.97)\end{array}$ & $\begin{array}{c}1.62 \\
(0.62)\end{array}$ & 0.07 & 0.22 & 0.06 \\
\hline $\begin{array}{l}\text { Weight } \\
(\mathrm{kg})\end{array}$ & $\begin{array}{c}75.46 \\
(15.79)\end{array}$ & $\begin{array}{c}63.40 \\
(14.95)\end{array}$ & $\begin{array}{c}73.46 \\
(12.95)\end{array}$ & $\begin{array}{c}71.44 \\
(13.06)\end{array}$ & 0.15 & 0.53 & 0.30 \\
\hline $\begin{array}{l}\text { Baecke } \\
\text { (points) }\end{array}$ & $\begin{array}{c}7.59 \\
(6.59)\end{array}$ & $\begin{array}{c}4.86 \\
(4.53)\end{array}$ & $\begin{array}{c}4.05 \\
(2.34)\end{array}$ & $\begin{array}{c}4.02 \\
(3.79)\end{array}$ & 0.14 & 0.36 & 0.14 \\
\hline $\begin{array}{l}\text { MMSE } \\
\text { (points) }\end{array}$ & $\begin{array}{l}28.50 \\
(1.58)\end{array}$ & $\begin{array}{l}26.14 \\
(3.43)\end{array}$ & $\begin{array}{l}27.40 \\
(2.01)\end{array}$ & $\begin{array}{l}27.88 \\
(1.69)\end{array}$ & 0.21 & 0.66 & 0.06 \\
\hline $\begin{array}{l}\text { Attention } \\
\text { (absolute) }\end{array}$ & $\begin{array}{l}19.00 \\
(3.36)\end{array}$ & $\begin{array}{l}12.85 \\
(6.41)\end{array}$ & $\begin{array}{l}19.80 \\
(9.43)\end{array}$ & $\begin{array}{l}18.11 \\
(5.71)\end{array}$ & 0.08 & 0.18 & 0.32 \\
\hline $\begin{array}{l}\text { WCST } \\
(\%)\end{array}$ & $\begin{array}{c}50.03 \\
(19.20)\end{array}$ & $\begin{array}{c}52.79 \\
(12.44)\end{array}$ & $\begin{array}{c}37.14 \\
(13.09)\end{array}$ & $\begin{array}{c}47.19 \\
(11.66)\end{array}$ & 0.20 & 0.07 & 0.46 \\
\hline $\begin{array}{l}\text { HADS-A } \\
\text { (points) }\end{array}$ & $\begin{array}{c}6.00 \\
(5.37)\end{array}$ & $\begin{array}{c}7.00 \\
(3.41)\end{array}$ & $\begin{array}{c}5.80 \\
(3.39)\end{array}$ & $\begin{array}{c}5.77 \\
(3.56)\end{array}$ & 0.72 & 0.60 & 0.71 \\
\hline $\begin{array}{l}\text { HADS-D } \\
\text { (points) }\end{array}$ & $\begin{array}{c}6.40 \\
(4.51)\end{array}$ & $\begin{array}{c}6.28 \\
(3.98)\end{array}$ & $\begin{array}{c}5.40 \\
(4.29)\end{array}$ & $\begin{array}{c}6.66 \\
(3.42)\end{array}$ & 0.67 & 0.82 & 0.62 \\
\hline $\begin{array}{l}\text { Age of } \\
\text { onset } \\
\text { (years) }\end{array}$ & $\begin{array}{l}63.40 \\
(4.74)\end{array}$ & $\begin{array}{l}67.28 \\
(5.90)\end{array}$ & $\begin{array}{l}62.90 \\
(7.51)\end{array}$ & $\begin{array}{l}70.11 \\
(7.07)\end{array}$ & 0.01 & 0.68 & 0.24 \\
\hline $\begin{array}{l}\text { HY } \\
\text { (points) }\end{array}$ & $\begin{array}{c}1.40 \\
(0.21)\end{array}$ & $\begin{array}{c}2.28 \\
(0.39)\end{array}$ & $\begin{array}{l}1.35 \\
(0.24)\end{array}$ & $\begin{array}{c}2.05 \\
(0.16)\end{array}$ & $<0.001$ & 0.11 & 0.30 \\
\hline $\begin{array}{l}\text { UPDRS } \\
\text { (points) }\end{array}$ & $\begin{array}{l}36.00 \\
(7.24)\end{array}$ & $\begin{array}{l}47.71 \\
(6.23)\end{array}$ & $\begin{array}{c}32.20 \\
(10.06)\end{array}$ & $\begin{array}{l}36.88 \\
(2.47)\end{array}$ & $<0.001$ & 0.07 & 0.29 \\
\hline $\begin{array}{l}\text { UPDRS- } \\
\text { III } \\
\text { (points) }\end{array}$ & $\begin{array}{l}20.10 \\
(6.44)\end{array}$ & $\begin{array}{l}30.14 \\
(5.87)\end{array}$ & $\begin{array}{l}18.60 \\
(6.83)\end{array}$ & $\begin{array}{l}24.55 \\
(2.00)\end{array}$ & $<0.001$ & 0.11 & 0.30 \\
\hline
\end{tabular}

MMSE: Mini-Mental State Examination; HADS-A: Hospital Anxiety and Depression Scale - Anxiety; HADS-D: Hospital Anxiety and Depression Scale - Depression; HY: Hoehn and Yahr scale; UPRDS: Unified Parkinson's disease scale; UPRDS-III: motor section of UPRDS; Stage: $p$ value of stage factor; Subtype: $\mathrm{p}$ value of subtype factor; Stage x Subtype: interaction between factors; Significant $\mathrm{p}$ values are bolded. 

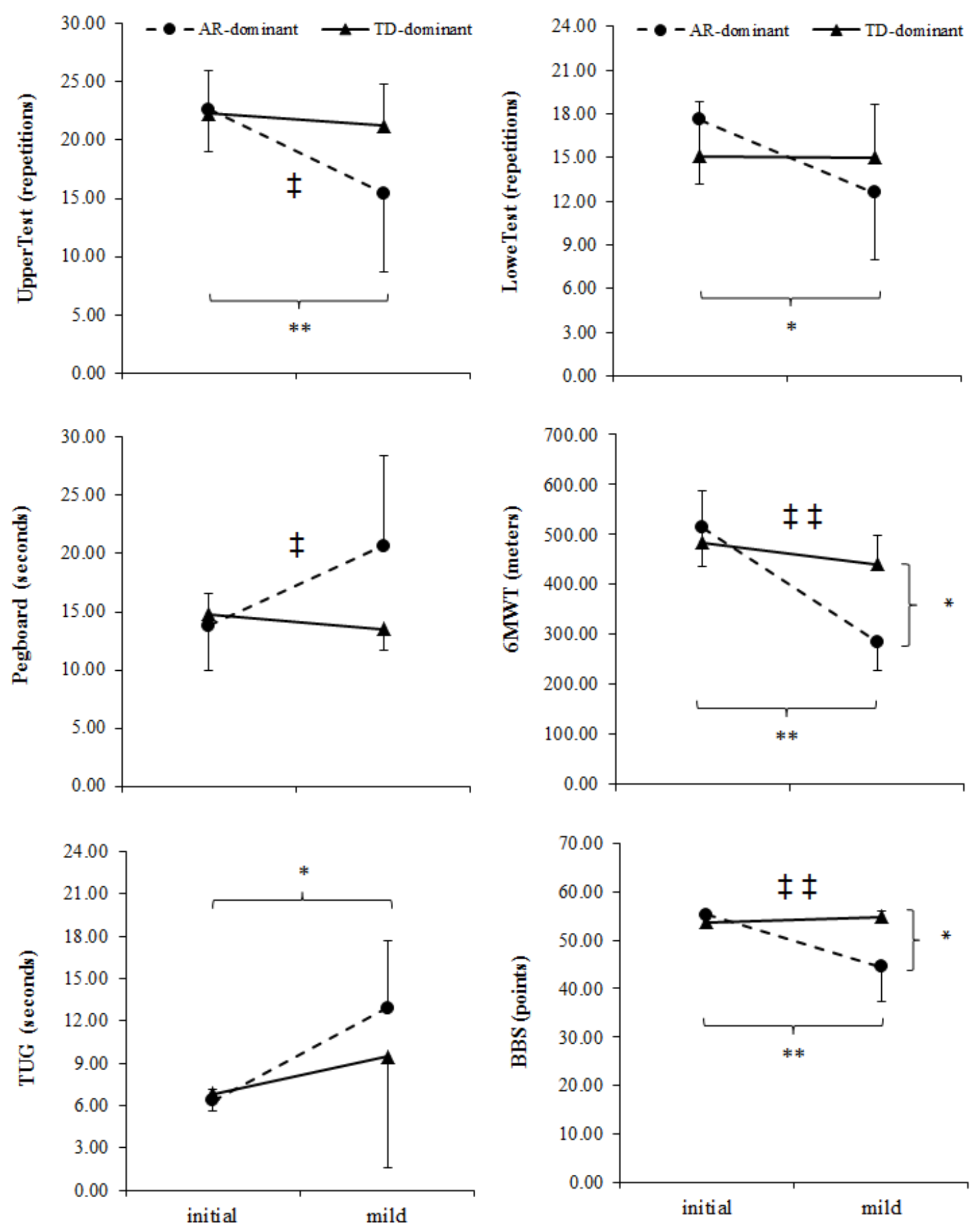

Figure 1. Performance of all physical capacity components. 
Table 2. Correlation coefficients between clinical outcomes and performance of functional capacity tests.

\begin{tabular}{lcccccc}
\hline & UpperTest & LowerTest & Pegboard & 6MWT & TUG & BBS \\
\hline $\begin{array}{l}\text { AR-dominant } \\
\text { Age }\end{array}$ & 0.14 & -0.19 & 0.19 & 0.05 & 0.42 & -0.20 \\
$\quad \begin{array}{l}\text { (years) } \\
\quad \begin{array}{l}\text { Age of onset } \\
\text { (years) }\end{array}\end{array}$ & 0.11 & -0.08 & 0.22 & -0.16 & $\mathbf{0 . 5 2}$ & -0.36 \\
$\begin{array}{l}\text { HY } \\
\text { (points) }\end{array}$ & $\mathbf{- 0 . 6 5}$ & $\mathbf{- 0 . 5 6}$ & $\mathbf{0 . 4 4}$ & $\mathbf{- 0 . 7 9}$ & $\mathbf{0 . 6 8}$ & $\mathbf{- 0 . 7 5}$ \\
$\begin{array}{l}\text { UPDRS-III } \\
\text { (points) }\end{array}$ & $\mathbf{- 0 . 6 9}$ & -0.39 & $\mathbf{0 . 6 5}$ & $\mathbf{- 0 . 7 6}$ & $\mathbf{0 . 5 2}$ & $\mathbf{- 0 . 5 9}$ \\
$\begin{array}{l}\text { TD-dominant } \\
\text { Age }\end{array}$ & & & & & & \\
$\quad \begin{array}{l}\text { (years) } \\
\text { Age of onset }\end{array}$ & 0.00 & -0.38 & -0.04 & -0.24 & 0.00 & $\mathbf{- 0 . 4 8}$ \\
$\begin{array}{l}\text { (years) } \\
\text { HY } \\
\text { (points) }\end{array}$ & 0.07 & -0.31 & -0.29 & -0.27 & 0.11 & -0.19 \\
$\begin{array}{l}\text { UPDRS-III } \\
\text { (points) }\end{array}$ & -0.30 & 0.06 & -0.03 & -0.18 & $\mathbf{0 . 4 6}$ & 0.40 \\
\hline
\end{tabular}

AR: akinetic-rigid subgroup; TD: tremor-dominant subgroup; For variables abbreviation see Methods section. Significant correlations are bolded.

Jankovic \& Kapadia, 2001). However, these studies failed to consider some patient characteristics which are decisive to motor performance such as age, age at the onset of disease or even UPRDS score. The subgroups in these studies were not similar in these characteristics (Alves et al., 2006; Gray et al., 2009). Thus, our study presents a different approach: when evaluating all groups with the same anthropometric and clinical characteristics (with the obvious differences between HY and UPRDS scores for different disease stages) we assure that these features are not responsible for our results.

One theory raised by some researchers is that AR patients' disease evolution is steeper than TD because they have more dispersed brain lesions, affecting the frontal and motor cortex (Bonnet, 2000; Helmich et al., 2012). Also, these lesions tend to be greater in number as the disease advances (Helmich et al., 2012) and this was used by Barbieri et al. (2012) to explain the poorer performance on physical capacity components of patients at higher disease stages. Therefore, in a first sense, this theory could be used to explain why mild AR patients show a higher decrease in the performance of physical components tests than TD.

However, our results on patients' cognitive status do not confirm this hypothesis. Since AR patients have a greater number of lesions in the cortical areas, especially the frontal cortex, it would be expected that they would also perform poorly on the cognitive tests, since this performance is directly related to cortical lesions (Calabresi, Picconi, Parnetti, \& Di Filippo, 2006; Owen, 2004). Therefore, considering that patients in both subgroups have the same cognitive and clinical status and are generally the same age, yet they behave differently as the disease advances, it is suggested that other features are responsible for these results. Since both subgroups have different biochemical profiles, one possible explanation for our results is that the factors responsible for the AR profile could accelerate the physiological ageing process. This is supported by the notion that despite the development of disease earlier in TD, patients of both groups have the same age at death (Helmich et al., 2012). However this is a theory that needs to be investigated and therefore, no firm statements can be made at this time.

This study has some limitations such as the low number of subjects and its cross-sectional design, which in a longitudinal investigation could reveal new and more precise information about the progression of disease as shown by the physical capacity components of both PD subtypes. However, we were successful in demonstrating that AR and 
TD patients behave differently as the disease progresses. Hence, we showed that it is highly valuable to consider both the disease subtype and stage in day-to-day life at the clinic to precisely prescribe exercises fit to the needs of each patient.

\section{Conclusion}

In conclusion, akinetic-rigid and tremor-dominant PD subgroups are different in the performance of some physical capacity components, but mainly, this performance worsen in the first group with the increase of disease severity, what is not the case in the second one. The reason to such results could not be confirmed in this study, but its importance is clear to clinical day-life. We showed that patients in specific disease stage and belonging to specific subgroup have different needs and therefore, the prescription of exercise programs should consider such features.

\section{References}

Alves, G., Larsen, J. P., Emre, M., Wentzel-Larsen, T., \& Aarsland, D. (2006). Changes in motor subtype and risk for incident dementia in Parkinson's disease. Movement Disorder, 21(8), 1123-1130. doi: 10.1002/mds.20897

ATS statement: guidelines for the six-minute walk test. (2002). American Journal of Respiratory Critical Care Medicine, 166(1), 111-117.

Barbieri, F. A., Rinaldi, N. M., Santos, P. C., Lirani-Silva, E., Vitorio, R., Teixeira-Arroyo, C., . . Gobbi, L. T. (2012). Functional capacity of Brazilian patients with Parkinson's disease (PD): relationship between clinical characteristics and disease severity. Archives of Gerontology and Geriatrics, 54(2), e83-88. doi: 10.1016/j.archger.2011.07.008

Benninger, D. H., Thees, S., Kollias, S. S., Bassetti, C. L., \& Waldvogel, D. (2009). Morphological differences in Parkinson's disease with and without rest tremor. Journal of Neurology, 256(2), 256-263. doi: 10.1007/s00415-009-0092-2

Bonnet, A. M. (2000). Involvement of non-dopaminergic pathways in Parkinson's disease: pathophysiology and therapeutic implications. CNS Drugs, 13, 351-364.

Bryden, P. J., \& Roy, E. A. (2005). Unimanual performance across the age span. Brain and Cognition, 57(1), 26-29. doi: 10.1016/ j.bandc.2004.08.016

Burn, D. J., Landau, S., Hindle, J. V., Samuel, M., Wilson, K. C., Hurt, C. S., \& Brown, R. G. (2012). Parkinson's disease motor subtypes and mood. Movement Disorders, 27(3), 379-386. doi: $10.1002 / \mathrm{mds} .24041$

Calabresi, P., Picconi, B., Parnetti, L., \& Di Filippo, M. (2006). A convergent model for cognitive dysfunctions in Parkinson's disease: the critical dopamine-acetylcholine synaptic balance. Lancet Neurology, 5(11), 974-983. doi: 10.1016/S14744422(06)70600-7

Eggers, C., Kahraman, D., Fink, G. R., Schmidt, M., \& Timmermann, L. (2011). Akinetic-rigid and tremor-dominant Parkinson's disease patients show different patterns of FPCIT single photon emission computed tomography. Movement Disorders, 26(3), 416-423. doi: 10.1002/mds.23468

Folstein, M. F., Folstein, S. E., \& McHugh, P. R. (1975). "Minimental state". A practical method for grading the cognitive state of patients for the clinician. Journal of Psychiatric Research, 12(3), 189-198.

Gobbi, L., Barbieri, F., Vitório, R., Pereira, M., \& Teixeira-Arroyo, C. (2011). Effects of a Multimodal Exercise Program on Clinical, Functional Mobility and Cognitive Parameters of Idiopathic Parkinson's Disease Patients. In A. Lazinica (Ed.), Parkinson's Disease / Book 6: InTech.

Goetz, C. G., Poewe, W., Rascol, O., Sampaio, C., Stebbins, G. T., Counsell, C., . . Seidl, L. (2004). Movement Disorder Society Task Force report on the Hoehn and Yahr staging scale: status and recommendations. Movement Disorders, 19(9), 1020-1028. doi: $10.1002 / \mathrm{mds} .20213$

Gray, W. K., Hildreth, A., Bilclough, J. A., Wood, B. H., Baker, K., \& Walker, R. W. (2009). Physical assessment as a predictor of mortality in people with Parkinson's disease: a study over 7 years. Movement Disorders, 24(13), 1934-1940. doi: $10.1002 / \mathrm{mds} .22610$

Heaton, R., Chelune, G., Tlley, J., Kay, G., \& Curtiss, G. (1993). Wisconsin card sorting test manual. USA: Psychological Assessment Resources.

Helmich, R. C., Hallett, M., Deuschl, G., Toni, I., \& Bloem, B. R. (2012). Cerebral causes and consequences of parkinsonian resting tremor: a tale of two circuits? Brain. doi: 10.1093/ brain/aws 023

Helmich, R. C., Janssen, M. J., Oyen, W. J., Bloem, B. R., \& Toni, I. (2011). Pallidal dysfunction drives a cerebellothalamic circuit into Parkinson tremor. Annals of Neurology, 69(2), 269-281. doi: 10.1002/ana.22361

Hoehn, M. M., \& Yahr, M. D. (1967). Parkinsonism: onset, progression and mortality. Neurology, 17(5), 427-442.

Jankovic, J., \& Kapadia, A. S. (2001). Functional decline in Parkinson disease. Archives of Neurology, 58(10), 1611-1615.

Lewis, Du, G., Sen, S., Kawaguchi, A., Truong, Y., Lee, S., . . . Huang, X. (2011). Differential involvement of striato- and cerebello-thalamo-cortical pathways in tremor- and akinetic/ rigid-predominant Parkinson's disease. Neuroscience, 177, 230239. doi: 10.1016/j.neuroscience.2010.12.060

Lewis, S. J., Foltynie, T., Blackwell, A. D., Robbins, T. W., Owen, A. M., \& Barker, R. A. (2005). Heterogeneity of Parkinson's disease in the early clinical stages using a data driven approach. Journal of Neurology, Neurosurgery, and Psychiatry, 76(3), 343-348. doi: 10.1136/jnnp.2003.033530

Olanow, C. W., Stern, M. B., \& Sethi, K. (2009). The scientific and clinical basis for the treatment of Parkinson disease (2009). Neurology, 72(21 Suppl 4), S1-136. doi: 10.1212/ WNL.0b013e3181a1d44c

Osness, W., Adrian, M., B, C., Hoeger, W., Raab, D., \& Wiswell, R. (1990). Functional fitness assessment for adults over 60 years (a field based assessment). Reston: American Alliance for Health, Physical Education, Recreation and Dance

Owen, A. M. (2004). Cognitive dysfunction in Parkinson's disease: the role of frontostriatal circuitry. Neuroscientist, 10(6), 525537. doi: $10.1177 / 1073858404266776$

Paolo, A. M., Troster, A. I., Axelrod, B. N., \& Koller, W. C. (1995). Construct validity of the WCST in normal elderly and persons with Parkinson's disease. Archives of Clinical Neuropsychology, 10(5), 463-473.

Podsiadlo, D., \& Richardson, S. (1991). The timed "Up \& Go": a test of basic functional mobility for frail elderly persons. Journal of the American Geriatrics Society, 39(2), 142-148.

Qutubuddin, A. A., Pegg, P. O., Cifu, D. X., Brown, R., McNamee, S., \& Carne, W. (2005). Validating the Berg Balance Scale for patients with Parkinson's disease: a key to rehabilitation 
evaluation. Archives of Physical Medicine and Rehabilitation, 86(4), 789-792. doi: 10.1016/j.apmr.2004.11.005

Rantanen, T., Guralnik, J. M., Sakari-Rantala, R., Leveille, S., Simonsick, E. M., Ling, S., \& Fried, L. P. (1999). Disability, physical activity, and muscle strength in older women: the Women's Health and Aging Study. Archives of Physical Medicine and Rehabilitation, 80(2), 130-135.

Rikli, R. E., \& Jones, C. J. (1999). Development and validation of a functional fitnesstest for community residing older adults. Journal of Aging and Physical Activity, 7, 129-161.

Scalzo, P. L., Nova, I. C., Perracini, M. R., Sacramento, D. R., Cardoso, F., Ferraz, H. B., \& Teixeira, A. L. (2009). Validation of the Brazilian version of the Berg balance scale for patients with Parkinson's disease. Arquives of Neuropsiquiatry, 67(3B), 831-835.

Spreen, O., \& Strauss, E. (1998). A compendium of neuropsychological tests: Administration, norms and commentary. New York: Oxford University Press.

The Unified Parkinson's Disease Rating Scale (UPDRS): status and recommendations. (2003). Movement Disorders, 18(7), 738-750. doi: 10.1002/mds. 10473

Voorrips, L. E., Ravelli, A. C., Dongelmans, P. C., Deurenberg, P., \& Van Staveren, W. A. (1991). A physical activity questionnaire for the elderly. Medicine and Science in Sports and Exercise, 23(8), 974-979.

Waters, C. H. (2008). Diagnosis and management of Parkinson's Disease (Vol. 6). Caddo: Professional Communications.

Zigmond, A. S., \& Snaith, R. P. (1983). The hospital anxiety and depression scale. Acta Psychiatrica Scandinavica, 67(6), 361370.

\section{Authors' note}

\section{Correspondence}

Marcelo P. Pereira

E-mail: mppereir@yahoo.com.br

\section{Acknowledgments}

Fundação de Amparo a Pesquisa do Estado de São Paulo, FAPESP

This study was presented at the $8^{\text {th }}$ International Congress of Physical Education and Human Movement and $14^{\text {th }}$ Symposium Paulista Physical Education.

Declaration of Conflicting Interests: The authors declared no conflicts of interest exist with respect to the research, authorship, and/or publication of this article.

Manuscript received on February 13, 2013

Manuscript accepted on April 18, 2013 